\title{
Effective Lighting Design Standards Impacting Patient Care: A Systems Approach
}

\author{
Sameer Mehrotra, Sunil Basukala*, Shiva Devarakonda \\ Department of Hospital Administration, Armed Forces Medical College (AFMC), Pune, Maharashtra \\ Email: "anyurysm@gmail.com
}

Received 27 September 2015; accepted 3 November 2015; published 6 November 2015

Copyright (C 2015 by authors and Scientific Research Publishing Inc.

This work is licensed under the Creative Commons Attribution International License (CC BY).

http://creativecommons.org/licenses/by/4.0/

(c) (i) Open Access

\begin{abstract}
Background: Most healthcare settings are lit by a combination of daylight entering through windows, skylights and electric-light sources. It is important to understand how these two types of light sources differ to understand their relative impacts on human health and performance. It is found important to have a starting point in healing architecture and create an environment with knowledge of users sensory and functionally needs and looks at how hospital wards can support patients' experience or maybe even have a positive influence on the recovery process. Methods: $A$ systematic review of the literature to evaluate the impact of light on the quality of healthcare services was conducted. Several databases were systematically searched and evaluated. Results: Majority of the studies showed that distributions of light within a space in hospitals could substantially influence the health as well as perception of people within it. The study showed that in a multi-function and diverse habitant environment such as hospital treatment rooms, lighting system design plays a major role for comfort of the patients, the critical visual requirements for hospital staff, the comfort and visual need of the visitors. In addition to these goals, energy cost savings through the careful design of lighting schemes used in such applications. Conclusions: There is consistent evidence that shows the technical, architectural and energy aspects of providing optimal lighting conditions in different areas of a healthcare facility are important for patient, staff and energy conservation and cost within the hospitals.
\end{abstract}

\section{Keywords}

Hospital Lighting, LED, Energy Saving, Circadian Rhythm

\section{Introduction}

Light is critical to human functioning in that it allows us to see things and perform activities. But it is also im-

*Corresponding author.

How to cite this paper: Mehrotra, S., Basukala, S. and Devarakonda, S. (2015) Effective Lighting Design Standards Impacting Patient Care: A Systems Approach. Journal of Biosciences and Medicines, 3, 54-61.

http://dx.doi.org/10.4236/jbm.2015.311006 
portant because it affects human beings psychologically and physiologically. Several studies have documented the importance of light in reducing depression, decreasing fatigue, improving alertness, modulating circadian rhythms, and treating conditions such as hyper-bilirubinemia among infants [1].

Further, the presence of windows in the workplace and access to daylight have been linked with increased satisfaction with the work environment. Studies also show that adequate light levels are linked to reduced medication-dispensing errors in pharmacies. Thus, incorporating light into healthcare settings can be beneficial for patients as well as the staff who work there [2].

Most healthcare settings, as well as other buildings, are lit by a combination of daylight entering through windows and skylights and electric-light sources. It is important to understand how these two types of light sources differ to understand their relative impacts on human health and performance [3] [4]. Sunlight provides a balanced spectrum of colors with elements in all parts of the visible wavelength range. The actual wavelengths present in daylight vary over the day with latitude, meteorological conditions, and seasons [5].

In contrast, lights from most artificial electric-light sources, such as cool white fluorescent light and incandescent lights, are composed of wavelengths of lights that are concentrated in limited areas of the visible light spectrum, for example, yellow to red end or orange to red end of the spectrum. Full-spectrum electric-light sources such as xenon lamps and some filtered incandescent lights that have a spectral content similar to daylight, though their spectral content does not vary over time, are now available. Studies suggest that daylight is not inherently superior to artificial lighting for performance of most visual tasks. However, natural light has benefits over electric light sources in regulating circadian rhythms and maintaining overall health [6].

Hospital lighting system has two main functions: one is to meet the task requirements in each area of the hospital and the second is to create an environment that is visually satisfying the patients as a good lighting system design can influence human emotions and feelings of well-being [7].

\section{Requirement of the Hospital Lighting: [8]-[11]}

i) For the Patients: The physical environment in which a patient receives care affects patient outcomes, patient satisfaction and safety of patients. Patients require a quality lighting environment.

ii) For Staff: From the staff perspective, the visual environment should be conducive to for working. A welldesigned working environment can aid recruitment and the retention of staff as well as improving their morale.

iii) For the caretakers of patients: Their needs differ from those of hospital staff and professionals as caretakers may try to sleep during the night rather than try to stay awake.

Studies show that, there are four situations in which lighting installations may cause visual discomfort. They are:

a) Visual task difficulty, in which the lighting makes the required information difficult to extract, under or over stimulation, in which the visual environment is such that it presents too little or too much information,

b) Distraction, in which the observer's attention is drawn to objects that do not contain the information being sought

c) Perceptual confusion, in which the pattern of illuminance can be confused with the pattern of reflectance in the visual environment.

Energy efficiency can be achieved by using the most effective and efficient lighting equipment and control that can keep the energy requirement minimum whilst achieving the lighting design objectives [12] [13].

\section{Lighting System Design [14]}

Luminous intensity, luminance, luminous flux and illuminance are the four basic parameters used in lighting system design. Different types of lamps used in lighting system design with their luminous efficiency and lamp service life is given in Table 1.

The various factors to be considered in the design of lighting system for hospitals are:

i) Natural Illumination: The provision of natural illumination and access to windows is always appreciated by patients and should be considered in the design. Also it is required to limit sun penetration so that thermal and visual discomforts do not occur.

ii) Artificial Illumination: As the common lines of sight for the patient in the hospital is toward the ceiling and the top portion of the opposite walls, design should avoid glare to patients, while still providing good visibility to hospital professionals. A limiting glare index is recommended for each application. 
Table 1. Technical specification of surgical lights.

\begin{tabular}{|c|c|c|c|c|}
\hline S. No & Hospital environment & Lighting specification & Illuminance( lux) & Color rendition(Ra) \\
\hline 1 & $\begin{array}{c}\text { Reception } \\
\text { Waiting rooms/day rooms }\end{array}$ & Relaxing & 200 & 80 \\
\hline 2 & $\begin{array}{c}\text { Corridors } \\
\text { Day } \\
\text { Night }\end{array}$ & Transportation areas & $\begin{array}{c}200 \\
50\end{array}$ & $\begin{array}{l}80 \\
80\end{array}$ \\
\hline 3 & $\begin{array}{l}\text { Offices (clinical) } \\
\text { General } \\
\text { Examination }\end{array}$ & Multipurpose use & $\begin{array}{c}300 \\
1000\end{array}$ & $\begin{array}{l}80 \\
90\end{array}$ \\
\hline 4 & $\begin{array}{c}\text { Examination rooms } \\
\text { General } \\
\text { Examination }\end{array}$ & Visual inspections & $\begin{array}{c}500 \\
1000\end{array}$ & $\begin{array}{l}90 \\
90\end{array}$ \\
\hline 5 & $\begin{array}{c}\text { Patient rooms \& wards } \\
\text { General } \\
\text { Reading } \\
\text { Simple examination } \\
\text { Examinations/treatment } \\
\text { Night/observation } \\
\text { Bathroom and toilets }\end{array}$ & Multi task & $\begin{array}{c}100 \\
300 \\
300 \\
1000 \\
5 \\
200\end{array}$ & $\begin{array}{l}80 \\
80 \\
80 \\
90 \\
80 \\
80\end{array}$ \\
\hline
\end{tabular}

Colour rendering requirements: The ability of a light source to render colours of surfaces accurately can be conveniently quantified by The Commission Internationale de l'Eclairage (CIE) general colour rendering index. The colour rendering index is used to compare the colour rendering characteristics of various types of lamp.

Colour temperature $\left(\mathrm{T}_{\mathrm{c}}\right)$ :

As an object is heated, the emission spectrum alters. Warmer colours (yellow-red) appear at lower temperature of 1000 to 3000 kelvin, whereas at higher temperature of 5000 kelvin and above, cooler colours (greenblue) are seen (Figure 1).

Depth of illuminance:

Often manufacturers will also indicate the depth of illumination; this is the distance under the light emitting area where the illumination reaches $20 \%$ of the central illuminance (which is the illuminance at a distance of one meter from the lamp). Two figures are cited, $\mathrm{L}_{1}$ above the central illuminance and $\mathrm{L}_{2}$ below it. Both are expressed in mm and are shown in Figure 2.

Wherever possible in healthcare settings proponents of full-spectrum fluorescent lighting with a full-spectral wavelength similar to natural light and good color rendering and bright, changing, visual environments are to be provided (Table $2 \&$ Table 3 ).

There are ranges of technical specifications which are important to be aware of when making purchasing decisions. Typically three basic lamp types are used with in the operating theatre environment; these are incandescent, gas discharge and light emitting diodes (LED) (Table 4).

\section{Impact of Light in Human Health and Performance}

Light impacts human health and performance by following mechanisms:

a) Enabling performance of visual tasks

The most obvious effect of light on humans is in enabling vision and performance of visual tasks. The nature of the task —as well as the amount, spectrum, and distribution of the light—determines the level of performance that is achieved. Performance on visual tasks gets better as light levels increase. The work environment for nurses and physicians in hospitals is stressful [2]. Another factor that affects performance on visual tasks is age, and the need for light increases as a function of age due to reduced transmittance of aging eye lenses [6].

b) Controlling the body's circadian system

Light falling on the retina and being transmitted to the hypothalamus controls the body's circadian rhythm (biological events that repeat themselves at regular intervals), which are responsible for synchronizing the body's internal clock to 24 hours. If the internal rhythms do not match the workday rhythms, which is the case for many healthcare workers, staff can feel drowsy, tired, and distracted. The human circadian system consists 


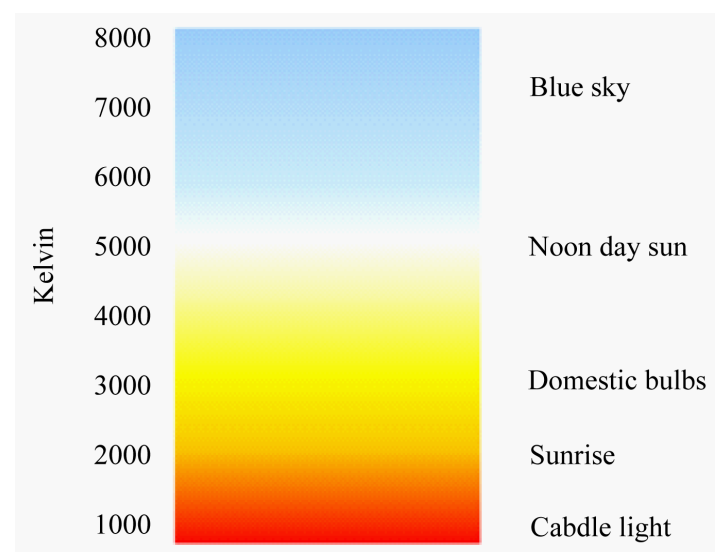

Figure 1. Colour temperature.

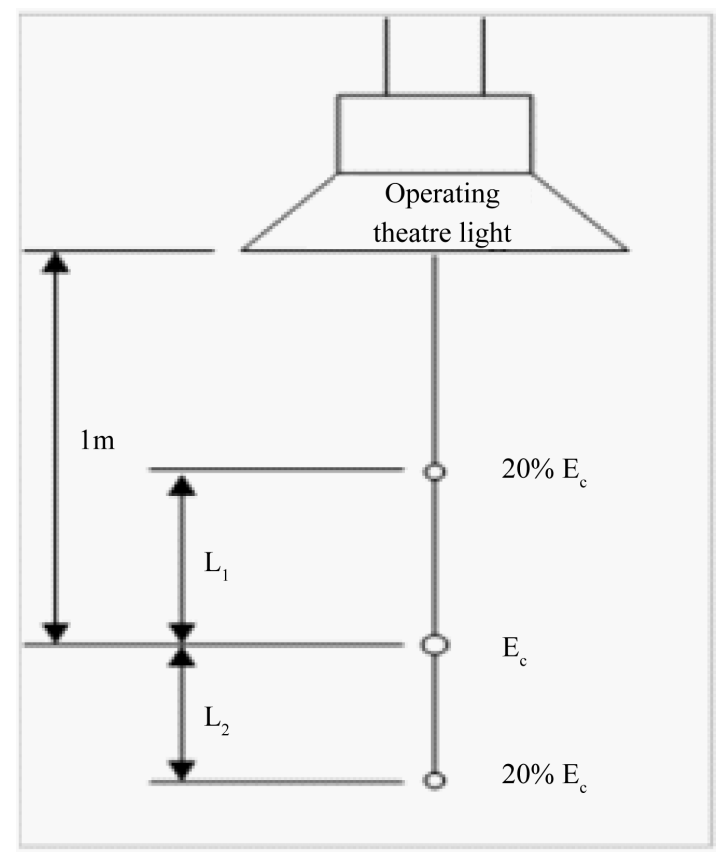

Figure 2. Depth of illuminance.

Table 2. Lighting specification for hospital departments.

\begin{tabular}{|c|c|c|c|c|}
\hline S. No. & Hospital environment & Lighting specification & $\begin{array}{l}\text { Illuminance } \\
\text { (lux) }\end{array}$ & $\begin{array}{c}\text { Color rendition } \\
\text { (Ra) }\end{array}$ \\
\hline \multirow{5}{*}{1} & Intensive care & \multirow{5}{*}{ Low level lighting } & & \\
\hline & General & & 400 & 90 \\
\hline & Simple examinations & & 400 & 90 \\
\hline & Examination/treatment & & 1000 & 90 \\
\hline & Night watch & & 20 & 90 \\
\hline \multirow{6}{*}{2} & Surgery \& outpatients & \multirow{6}{*}{ Specialized } & & \\
\hline & Pre-op/recovery & & 500 & \\
\hline & Operating theatre & & 1000 & 90 \\
\hline & Operating theatre-source & & 100,000 & 90 \\
\hline & At the body surface & & 40,000 & 90 \\
\hline & At the depth & & 8,000 & 90 \\
\hline
\end{tabular}


Table 3. Technical specification of surgical lights.

\begin{tabular}{cccc}
\hline \multirow{2}{*}{ S. No } & Requirements & \multicolumn{2}{c}{ Surgical luminaire } \\
\cline { 2 - 4 } 1 & Sterile handle( standard) & Minor treatment & Major and system \\
2 & Central illuminance $\left(\mathrm{E}_{\mathrm{c}}\right)$ & Yes & Yes \\
3 & Light field diameter $(\mathrm{d} 10)$ & $40,000-160,000$ & $-160,000$ \\
4 & Light distribution & Test value required & Test value required \\
5 & Shadow dilution & Test value required & Test value required \\
6 & Colour temperature $\left(\mathrm{T}_{\mathrm{c}}\right)$ & Test value required & Test value required \\
7 & Colour rendering index & $3000-6700$ kelvin & $3000-6700$ kelvin \\
8 & Maximum value for total irradiance $\mathrm{E}_{\mathrm{e}}$ & $85-100$ & $85-100$ \\
\hline
\end{tabular}

Table 4. Light differences based on lamp types.

\begin{tabular}{ccccc}
\hline S. No & Lamp type & Method of operation & End of life & Advantage/disadvantage \\
\hline 1 & Incandescent & Gas filled chamber \& burning filament & Burn out no-warning & $\begin{array}{c}\text { Excellent colour rendition } \\
\text { Large amount of heat produced }\end{array}$ \\
2 & Gas discharge & Electrical current passes through gas & Dims over time & $\begin{array}{r}\text { More light emitted than incandescent } \\
\text { More expensive }\end{array}$ \\
3 & LED & Semi-conductor & Dims over time & Do not generate heat \\
& & & & Fine adjustments to light \\
Small range of light emissions
\end{tabular}

of three components: an internal oscillator, which is located in the suprachiasmtic nucleus of the hypothalamus in the brain; a number of external oscillators (external stimuli such as light-dark cycle between day and night) that can reset (entrain) the internal oscillator; and a hormone, melatonin, secreted by the pineal gland that carries "time" information to all parts of the body through the bloodstream [15].

Light activation of the pineal gland results in the suppression of melatonin. Melatonin levels in the body determine a person's activity and energy level. Where daylight or artificial light is inadequate during the day, the natural suppression of melatonin production fails to occur and is accompanied by feelings of depression and sleepiness. High melatonin levels cause drowsiness, while low melatonin levels are related to a state of alertness [16] [17].

c) Reducing depression

At least 11 strong studies suggest that bright light is effective in reducing depression among patients with bipolar disorder or seasonal affective disorder (SAD). A majority of the studies have examined the impact of artificial bright light on reducing depression [15]. Benedetti and colleagues found that bipolar depressed inpatients in east-facing rooms (exposed to bright light in the morning) stayed an average of 3.67 days less in the hospital compared with similar patients who stayed in west-facing rooms [12]. An experimental study that compared the effect of morning and evening light on patients with winter depression found that morning light was twiceas effective as evening light in treating SAD [17].

d) Decreasing length of stay

A retrospective study of myocardial infarction patients in a cardiac intensive-care unit treated in either sunny rooms or dull rooms found that female patients stayed a shorter time in sunny rooms (2.3 days in sunny rooms, 3.3 days in dull rooms) [15]. Mortality in both sexes was consistently higher in dull rooms (39/335 dull, 21/293 sunny). Another study found that Veterans Health Administration medical centers located in warmer and drier climates had shorter length of stay of patients [18].

e) Lessening agitation

La Garcestudied the impact of environmental lighting interventionson agitated behaviors among residents with Alzheimer's disease. It found a significant drop in disruptive behaviors when residents were in the experi- 
mental setting (constant light levels) rather than the control setting (varying light levels) [19]. Exposure to bright morning light has been shown to reduce agitation among elderly patients with dementia. When elderly patients with dementia were exposed to 2500 lux for 2 hours in the morning for two 10-day periods, their agitation reduced. Patients were significantly more agitated on nontreatment days [20] [21].

f) Easing pain

A recent randomized prospective study assessed whether the amount of sunlight in a hospital room modifies a patient's psychosocial health, quantity of analgesic medication used, and pain medication cost. Patients undergoing elective cervical and lumbar spinal surgeries were admitted to the bright or the dim side of the same hospital unit postoperatively. This study found that patients exposed to an increased intensity of sunlight experienced less perceived stress, marginally less pain, took 22\% less analgesic medication per hour, and had 21\% less pain medication costs [22].

g) Affecting mood and perception

Studies have shown that people prefer daylight to artificial sources of light for work and like to be close to windows [23]. They also found that office occupants preferred daylight over electric lighting for seven different purposes: psychological comfort, office appearance and pleasantness, general health, visual health, color appearance of people and furnishings, work performance, and jobs requiring fine observation [24].

h) Affecting perceived stress and satisfaction

A study of 141 nurses in Turkey found that nurses who were exposed to daylight for at least 3 hours a day experienced less stress and were more satisfied at work [25] [26]. A survey conducted at a new medical center incorporating many daylight-enhancing features examined the impact of natural light on staff satisfaction. 43\% of the staff rated the increased natural light in the new facility as having a very positive impact on their work life, and $27 \%$ rated it as having a positive impact [27]. However, in most hospitals, nurses' stations and break rooms do not have windows or access to natural light. There is need for further research to understand the importance of natural light to staff, as well as the impact of artificial light on staff mood and performance [28] [29].

\section{Conclusions}

There is strong evidence that light is critical to human functioning and can be extremely beneficial to patients as well as staff in healthcare settings. Adequate lighting conditions are essential for performance of visual tasks by staff in hospitals, and poor lighting conditions can result in errors.

There is no doubt that lighting is an important factor for the hospital staff, patients and to the utilities provider. It helps hospital staff in performing their work and it also helps patients in their journey to speedy recovery. Therefore visual comfort and energy use shall be considered in determining the right type of light in the hospital lighting system design. Visual discomfort represented by some lighting features such as glare, hum, and flicker can cause health problems. Their negative effects such as straining the eyes, headaches, and eye irritation can lead to fatigue and attention deficit. Among the three light fixtures which are studied in this article, only LED lighting has the ability to eliminate these ailments. From visual comfort perspectives, LED can be considered the best choice in hospital lighting system design as the main cause of visual discomfort is not associated with it. Also, since DC voltage is used to power LED lights, it doesn't produce or cause flickering.

Hence, while making decisions regarding lighting, economic factors (first costs, energy consumption, and maintenance) must also be taken into consideration. Where good color rendering and bright, changing, and visual environments are desirable, energy-efficient natural light is ideal. Wherever possible in healthcare settings, natural light should be incorporated into lighting design not only because it is beneficial to patients and staff, but also because it is light delivered at no cost and in a form that is preferable to most people.

\section{References}

[1] Ulrich, R.S., Zimring, C., Joseph, A., Quan, X. and Choudhary, R. (2004) The Role of the Physical Environment in the Hospital of the 21st Century: A Once-in-a-Lifetime Opportunity. The Center for Health Design, Concord.

[2] Boyce, P., Hunter, C. and Howlett, O. (2003) The Benefits of Daylight through Windows. Rensselaer Polytechnic Institute, Troy.

[3] Rizzo, P., Rea, M.S. and White, R. (2010) In Newborn and Infant Nursing Reviews.

[4] Hilary, D., et al. (2006) Colour and Lighting in Hospital Design. Optic and Laser Technology, 38, 343-365.

http://dx.doi.org/10.1016/j.optlastec.2005.06.040 
[5] Ackerman, B., Sherwonit, E. and Fisk, W. (1989) Reduced Incidental Light Exposure: Effect on the Development of Retinopathy of Prematurity in Low Birth Weight Infants. Pediatrics, 83, 958-962.

[6] Edwards, L. and Torcellini, P. (2002) A Literature Review of the Effects of Natural Light on Building Occupants (Technical Report). National Renewable Energy Laboratory, Golden. http://dx.doi.org/10.2172/15000841

[7] Alimoglu, M.K. and Donmez, L. (2005) Daylight Exposure and the Other Predictors of Burnout among Nurses in a University Hospital. International Journal of Nursing Studies, 42, 549-555. http://dx.doi.org/10.1016/j.ijnurstu.2004.09.001

[8] Baehr, E., Fogg, L.F. and Eastman, C.I. (1999) Intermittent Bright Light and Exercise to Entrain Human Circadian Rhythms to Night Work. American Journal of Physiology, 277, 1598-1604.

[9] Beauchemin, K.M. and Hays, P. (1996) Sunny Hospital Rooms Expedite Recovery from Severe and Refractory Depressions. Journal of Affective Disorders, 40, 49-51. http://dx.doi.org/10.1016/0165-0327(96)00040-7

[10] Beauchemin, K.M. and Hays, P. (1998) Dying in the Dark: Sunshine, Gender and Outcomes in Myocardial Infarction. Journal of the Royal Society of Medicine, 91, 352-354.

[11] Begemann, S.H.A., van den Beld, G.J. and Tenner, A.D. (1997) Daylight, Artificial Light and People in an Office Environment: Overview of Visual and Biological Responses. International Journal of Industrial Ergonomics, 20, 231239. http://dx.doi.org/10.1016/S0169-8141(96)00053-4

[12] Benedetti, F., Colombo, C., Barbini, B., Campori, E. and Smeraldi, E. (2001) Morning Sunlight Reduces Length of Hospitalization in Bipolar Depression. Journal of Affective Disorders, 62, 221-223. http://dx.doi.org/10.1016/S0165-0327(00)00149-X

[13] Blackburn, S. and Patteson, D. (1991) Effects of Cycled Light on Activity State and Cardiorespiratory Function in Preterm Infants. Journal of Perinatal \& Neonatal Nursing, 4, 47-54. http://dx.doi.org/10.1097/00005237-199103000-00009

[14] Dumbleton, T., Clift, L., Bayer, S.H., Elton, E., Howarth, P.A. and Maguire, M. (2010) Buyers’ Guide: Operating Theatre Lighting. NHS Purchasing and Supply Agency, Chester and Reading.

[15] Beauchemin, K.M. and Hays, P. (1998) Dying in the Dark: Sunshine, Gender and Outcomes in Myocardial Infarction. Journal of the Royal Society of Medicine, 91, 352-354.

[16] Veitch, J.A. (1993) Conclusion: Is Full Spectrum Light the Quality Choice? (No. 659). Institute for Research in Construction, Ottawa.

[17] Lewy, A.J., Bauer, V.K., Cutler, N.L., Sack, R.L., Ahmed, S., Thomas, K.H., et al. (1998) Morning vs. Evening Light Treatment of Patients with Winter Depression. Archives of General Psychiatry, 55, 890-896. http://dx.doi.org/10.1001/archpsyc.55.10.890

[18] Federman, E.J., Drebing, C.E., Boisvert, C. and Penk, W. (2000) Relationship between Climate and Psychiatric Inpatient Length of Stay in Veterans Health Administration Hospitals. American Journal of Psychiatry, 157, 1669-1673. http://dx.doi.org/10.1176/appi.ajp.157.10.1669

[19] LaGarce, M. (2002) Control of Environmental Lighting and Its Effects on Behaviors of the Alzheimer's Type. Journal of Interior Design, 28, 15-25. http://dx.doi.org/10.1111/j.1939-1668.2002.tb00375.x

[20] Sloane, P.D., Mitchell, C.M., Preisser, J., Phillips, C., Commander, C. and Burker, E. (1998) Environmental Correlates of Resident Agitation in Alzheimer's Disease Special Care Units. Journal of the American Geriatrics Society, 46, 862869. http://dx.doi.org/10.1111/j.1532-5415.1998.tb02720.x

[21] Lovell, B.B., Ancoli-Israel, S. and Gevirtz, R. (1995) Effect of Bright Light Treatment on Agitated Behavior in Institutionalized Elderly Subjects. Psychiatry Research, 57, 7-12. http://dx.doi.org/10.1016/0165-1781(95)02550-G

[22] Walch, J.M., Rabin, B.S., Day, R., Williams, J.N., Choi, K. and Kang, J.D. (2005) The Effect of Sunlight on Postoperative Analgesic Medication Usage: A Prospective Study of Spinal Surgery Patients. Psychosomatic Medicine, 67, 156163. http://dx.doi.org/10.1097/01.psy.0000149258.42508.70

[23] Heerwagen, J. and Heerwagen, D. (1986) Lighting and Psychological Comfort. Lighting Design and Application, 6, 47-51.

[24] Leather, P., Pyrgas, M., Beale, D. and Lawrence, C. (1998) Windows in the Workplace: Sunlight, View, and Occupational Stress. Environment \& Behavior, 30, 739-762. http://dx.doi.org/10.1177/001391659803000601

[25] Alimoglu, M.K. and Donmez, L. (2005) Daylight Exposure and the Other Predictors of Burnout among Nurses in a University Hospital. International Journal of Nursing Studies, 42, 549-555. http://dx.doi.org/10.1016/j.ijnurstu.2004.09.001

[26] Miller, C.L., White, R., Whitman, T.L., O’Callaghan, M.F. and Maxwell, S.E. (1995) The Effects of Cycled versus Noncycled Lighting on Growth and Development in Preterm Infants. Infant Behavior and Development, 18, 87-95. http://dx.doi.org/10.1016/0163-6383(95)90010-1 
[27] Mroczek, J., Mikitarian, G., Vieira, E.K. and Rotarius, T. (2005) Hospital Design and Staff Perceptions: An Exploratory Analysis. Health Care Manager, 24, 233-244. http://dx.doi.org/10.1097/00126450-200507000-00008

[28] Oren, D.A., Wisner, K.L., Spinelli, M. and Epperson, N. (2002) An Open Trial of Morning Light Therapy for Treatment of Antepartum Depression. American Journal of Psychiatry, 159, 666-669. http://dx.doi.org/10.1176/appi.ajp.159.4.666

[29] Reynolds, J.D., Hardy, R.J., Kennedy, K.A. and Spencer, R. (1998) Lack of Efficacy of Light Reduction in Preventing Retinopathy of Prematurity. New England Journal of Medicine, 338, 1572-1576.

http://dx.doi.org/10.1056/NEJM199805283382202 